Marianne Lind. Conversation - more than words. A Norwegian case study of the establishment of a contribution in aphasic interaction. International Journal of Applied Linguistics, 2005, vol 15(2), pp 213-239.

This is an author produced version of the article. The original publication is available at http://www3.interscience.wiley.com/

http://dx.doi.org/10.1111/j.1473-4192.2005.00088.x

Access to the published version may require journal subscription.

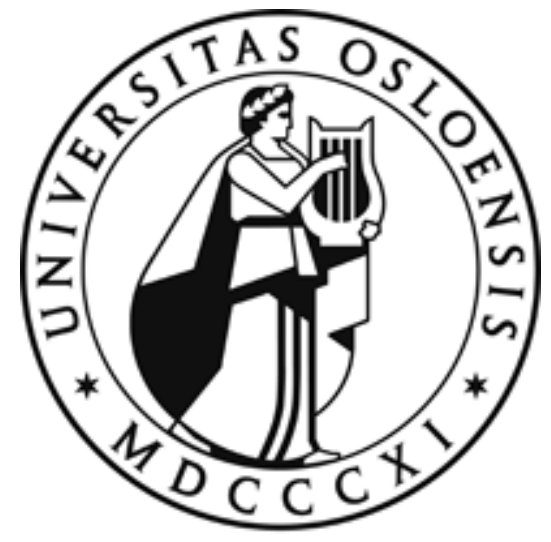




\title{
Conversation - more than words. A Norwegian case study of the establishment of a contribution in aphasic interaction
}

\author{
Marianne Lind Bredtvet Resource Centre
}

\begin{abstract}
The article presents an analysis of the means and processes through which an aphasic speaker with severe limitations in spontaneous speech production is able to make a self-initiated, substantial contribution in interaction with a non-aphasic interlocutor. The analytical process is based on the principles of conversation analysis, and the study draws on insights from interactional linguistics. The analysis illustrates the aphasic participant's ability to make himself understood by using several methods of communication and by situating his parts of the contribution in relation to the sequential context. Hence, the analysis reveals an essential form of orderliness and complementarity in what may initially seem like a disorderly piece of interaction. The analysis highlights the need for systematic, functional assessment of communicative and linguistic abilities in aphasia, a perspective with possible consequences for the training and practice of speech and language therapists.
\end{abstract}

\section{Introduction}

"One of the most human things that human beings do is talk to each other" (Labov and Fanshel 1977: 1). This simple truth seems no less apt as a starting point for studies of human interaction today than it was more than a quarter of a century ago. To be a human being essentially consists of participating in dialogical actions with other human beings. For different reasons, though, not all human beings are equally well able to participate in verbal conversation, the primordial type of dialogical or joint action (Clark 1996).

Different types of speech and language pathological disorders may cause difficulties with participation in conversational interaction. Systematic and 
comprehensive assessment of communicative abilities in a variety of settings - formal testing as well as functional observation - is indispensable for diagnostic as well as rehabilitation purposes and will provide valuable insights into a language disorder for the person affected as well as for friends, relatives and professionals. In this lies an important applied perspective of the exploratory and descriptive analysis presented below.

In a broader perspective, an intriguing question from an applied as well as from a theoretical perspective concerns the similarities and differences between structures and processes found in conversations involving language-impaired participants and conversations in which - for other reasons - the participants do not master the linguistic code to the same degree, for instance conversations involving young children (cf. e.g. Ochs and Schieffelin 1983) or non-native speakers (cf. e.g. Bremer et al. 1996). Comparative studies of conversations under such different types of specific conditions could presumably shed even more light on the basic social and cognitive mechanisms of interaction, which may then lead to a reconsideration of practices within several fields.

In this article, a short passage from a conversation between a severely aphasic man and a non-aphasic woman is analysed in order to detect and describe the means and processes through which a contribution by the aphasic speaker is established in the interaction. The term 'contribution' is used mainly in accordance with Linell (1998), referring to what is said or done during a turn at talk. Contributions normally consist of two basic properties: the act of referring and the act of predicating. Since the establishment of reference is far more complicated (and possibly also more basic to the process of intersubjective understanding; cf. Brown 1995: 64) than the act of predicating in the selected passage, only the reference part of the contribution will be analysed in the present article. The dialogical aspect of the establishment of a contribution (cf. Clark 1996) is also essential, not least in the particular type of conversation investigated here.

\section{Background and aims}

Aphasia may be defined as a complex of persisting language disorders caused by focal lesions to a mature brain (Lesser 1978) and may affect all the language modalities, although to different degrees in each individual. Since the knowledge and use of language is inextricably linked to identities and relationships, aphasia cannot, however, be regarded merely as a language disorder but also as a social problem with potentially serious implications for the quality of life of those affected (cf. e.g. Jordan and Kaiser 1996; Pound et al. 2000). 
Although different types of aphasia are distinguished, the disorder is characterised by great variation, inter-individually as well as intraindividually (Code 1989). To get a maximally comprehensive impression of the linguistic and communicative abilities and difficulties of an aphasic speaker for diagnostic and rehabilitation purposes, a triangulation of methods is needed. Tests and observations must be conducted in different contexts covering a multitude of linguistic tasks and communicative activities. Rehabilitation should be based on the communicative strength of the client, as assessed and documented in real-life communication as well as in test contexts. In recent years, more dialogical approaches to assessment and rehabilitation have been added to the traditional types of testing of linguistic abilities in aphasia (cf. e.g. Whitworth, Perkins and Lesser 1997; Lesser and Perkins 1999; Lock, Wilkinson and Bryan 2001).

There is a long tradition for linguistic analyses of aphasia (Caplan 1987); conversation analytic studies have a more recent history, dating from the early 1990s onwards (Damico, Oelschlaeger and Simmons-Mackie 1999). With a few exceptions (cf. e.g. Klippi 1996; Laakso 1997; Anward 2003), most of the studies within this field have been conducted on speakers of some variety of English. The present study thus adds to the existing literature on aphasia and conversation by offering a sequential analysis of Norwegian data.

Certain types of sequences are characteristic and constitutive of certain types of interactions or activities (Levinson 1992 [1979]). In interactions involving language-impaired participants, a type of sequence known as "hint-and-guess" sequences (Lubinski, Duchan and Weitzner-Lin 1980) is pervasive and has been analysed by for instance Linell (1991), Collins and Markovà (1995), Goodwin (1995), Laakso and Klippi (1999), Oelschlaeger and Damico (2003). Basically, these sequences consist of three moves: 1) the language-impaired participant produces a verbal and/or non-verbal sign with a form and/or function that is not immediately comprehensible to the interlocutor (the hint), 2) the co-participant makes a verbal guess at what is expressed by this hint, and 3) the language-impaired participant affirms or rejects the guess. In the case of a rejection, the sequence is recycled, usually until a guess has been provided which the language-impaired participant can accept. Laakso and Klippi (1999) distinguish four phases of hint-andguess sequences in interactions involving aphasic participants: a problemestablishment phase, a phase for establishing the collaborative coparticipation framework, a hint-and-guess phase, and a confirmation phase. In their description, these sequences arise as a result of persistent word finding difficulties and function as collaborative repair efforts.

In the present article, a hint-and-guess sequence from a conversation with a Norwegian aphasic speaker is analysed. In contrast with most other 
studies of such interactions, the participants did not know each other well beforehand. Neither did the non-aphasic participant have much practical experience with aphasia prior to this conversation. It will be argued that although necessarily arising from an underlying difficulty of word finding, this hint-and-guess sequence arises in a context in which there are no signs of an explicit search for words, marked by for instance gaze withdrawal, hesitation markers, metacommunicative expressions etc. Hence, there is no explicit problem-establishment phase. Furthermore, although the sequence on one level functions as a collaborative repair effort (cf. the underlying problem of word finding), the locally most relevant function of this sequence is that of establishing - collaboratively - a contribution initiated by the aphasic speaker. It is shown that hint-and-guess sequences may be interspersed with side sequences of different kinds. Finally, the analysis demonstrates that hint-and-guess phases can be locally manifested as two kinds of structures: as a tripartite structure or as a chain of adjacency pairs.

\section{Methodology and data}

The analysis is based on a short passage from an audio- and video-recorded conversation between a Norwegian man (A.) suffering from a non-fluent type of aphasia and a female non-aphasic co-participant (M.) (cf. Lind 2002a). The recording was made five years post-onset. A. experiences severe limitations in verbal conversational production, lexically as well as grammatically. His productive vocabulary is dominated by the response words ja 'yes', nei 'no' and variants of these, the personal pronoun jeg 'I', a few adjectives with fairly similar sematic content (fint, god, bra 'good, fine'), a conjunction (men 'but'), a fixed phrase (vet ikke 'don't know') and a couple of adverbs (akkurat 'exactly, precisely', der 'there'). His utterances in conversation are short and, consequently, sentence and phrase structure variety is reduced. His speech tempo is also reduced, although each single word is not produced particularly slowly.

Interacting conversationally with A., one experiences strongly that despite the severe linguistic difficulties, he is eager and able to take part in conversation, to take the initiative and give responses that are more elaborate than a simple 'yes' or 'no' (cf. Lind 2002a,b; Simonsen and Lind 2002). The main research question thus concerns an exploration of the means and methods by which this participation in conversational interaction is made possible.

To allow for analysis and documentation of the results, the conversation has been transcribed, following a simplified version of the system developed by $\mathrm{Du}$ Bois et al. (1993); cf. the Appendix for a key to the transcription 
symbols. The translations are meant to capture the content of the original, without aiming for idiomatic English. The analytical process is based on the principles of conversation analysis (cf. e.g. Pomerantz and Fehr 1997; ten Have 1999; Wilkinson 1999) in which a single case is sufficient to motivate analysis (Schegloff 1993). Below, an utterance-by-utterance analysis of the selected sequence is presented, allowing the reader an impression of the process of interactive understanding-in-context that the participants themselves were actually involved in.

\section{Preliminary presentation of the selected sequence}

The selected passage occurs quite early in a conversation between A. and M. Before meeting M., A. has been to the physiotherapist, and this is the topic of the talk leading up to the selected passage. They talk about the geographic location of the 'physiotherapy institute' and A.'s opinion of his physiotherapist before they turn to the physical state of the 'institute'. A. explains that the house is old and in need of renovation.

In the selected passage, A. attempts to establish a self-initiated contribution: he refers to someone, and he makes a statement about the referent. His contribution can be seen as an explanatory denial in response to a suggestion by $M$. that the physical surroundings may improve, as the owner may renovate the house. In retrospect, the content (obviously not the form) of A.'s contribution may be paraphrased as: 'No, it will not get better, because there is an old lady who owns the house, and she doesn't want to renovate it'. However, for the co-participant in this interaction, it is for a relatively long time neither clear who is being referred to, nor what kind of role the referent plays in A.'s contribution.

A.'s contribution can also be looked upon as an initiative. In response to M.'s suggestion about improvement, A. could have chosen to give a simple token of agreement or disagreement, thus leaving it to $\mathrm{M}$. to carry the topic further. However, he chooses to initiate a fairly complex utterance. In the selected passage, A. displays great eagerness in making M. understand him, as evidenced for instance in the fact that he does not give up his contribution or resort to any kind of avoidance strategies. This eagerness seems to be proportional with the importance he attaches to the topic, which again may be linked to the fact that he himself has initiated the subtopic of renovation. 


\section{Sequential analysis: the 'renovation' sequence as a course of action}

The prompting initiative and the establishment of a framework for coparticipation

$1 \mathrm{M}: \quad\{$ det kan jo hende at det blir bedre?\}

\{gaze contact\}

'it might get better though'

$2 \quad\{\{\ldots(1.8)\}\}$

$\{\{$ A starts withdrawing his gaze $\}\}$

$3 \quad\{$ eller?

\{A starts leaning forward

'or'

$4 \quad$... (0.9)\} \{\{kanskje ikke de har råd til å pusse det opp $\}\}$

$\{\{$ A: quick hand movement between table and himself, secures gaze contact again\}\}

'maybe they can't afford renovating it'

The sequence starts with a response-soliciting utterance from M. (line 1), to which there is no immediate response from A. Instead there is a 1.8 second pause (line 2) occurring in the slot for the second part of an adjacency pair. Since the pause is fairly long (cf. Jefferson 1989), it is heard as a marked absence of this second part, indicating some kind of problem in the interaction (cf. Pomerantz 1984: 152). M. pursues a response partly by producing a hedging particle (the tag-like eller 'or', line 3), and partly by offering a modified version of her original initiative (line 4). The way in which M. pursues a response suggests that she interprets A.'s lack of response as indicating some type of disagreement (Pomerantz 1984: 153).

Disagreement may not, however, be the only cause of a problem in this sequential position. Difficulties understanding the reference of a given term or wrong assumptions about what constitutes some particular piece of shared knowledge are other possibilities (Pomerantz 1984). In addition, pauses might be a sign of word finding difficulties (Goodwin and Goodwin 
1986). Given the aphasia, one might expect A. to have word finding difficulties and to display this in interaction. The question, then, is what does $\mathrm{A}$. do in the beginning of the sequence?

Even though A. does not present any verbal contribution in the first lines of the sequence, he starts a contribution non-verbally during the 1.8 second pause. This contribution consists of a withdrawal of gaze, a shift of posture (leaning forward, indicating more active involvement in the interaction), a hand gesture (a rapid pointing gesture, partly directed at the table, partly at himself), and a resumption of gaze contact.

These actions indicate an effort at taking the floor for an extended turn and securing the co-orientation of the co-participant. The shift of posture and the hand gesture both indicate an attempt at taking the floor and signalling that the table plays a role in the upcoming contribution. The temporary withdrawal of gaze can indicate a change of participant framework from a recipient role towards a production role. It can also be seen as a sign of word searching. However, even though the gaze is withdrawn from the co-participant, it is not without direction. Rather, it is directed at the table, the object being pointed at gesturally. Furthermore, eye contact is rapidly restored by A., thereby securing co-orientation from M. There are no unequivocal signals, then, from A. of word searching in this first part of the 'renovation' sequence. Rather, in this phase of the sequence, A. puts interactional efforts into establishing a framework for coparticipation, that is, a shared understanding of how the communicative labour is to be divided.

The first attempt at establishing reference: entering the phase of hintand-guess

$5 \mathrm{~A}:\{\ldots(2.4)\}$

\{A withdraws gaze, looks at the table, 'marks' a point with his index finger\}

$6 \quad\{\{h u n\}\}$

$\{$ \{A points to and looks at the table. M briefly looks at the table, then at $\mathrm{A}\}\}$

'she'

$7 \mathrm{M}: \quad \ldots(1.2) \quad\{j a ?\}$

\{gaze contact\}

'yes' 
$\{\{\mathrm{A}$ briefly looks at the table, then at $\mathrm{M}$, three finger taps on the table\}\}

'the physiotherapist'

$9 \mathrm{~A}:\{. . n e i$

'no'

$10 \mathrm{M}:(0)$ nei

'no'

In line 5, the floor is A.'s, and the initiation of his contribution is done in two steps: non-verbally with a pointing gesture at a specific point on the table (cf. Figure 1), and verbally with the pronoun hun 'she' pronounced with a falling pitch contour (line 6) (cf. Figure 2). This constitutes the first attempt at establishing reference. At this point, $\mathrm{M}$. is also looking at the table; hence, co-orientation has been established in the interaction.

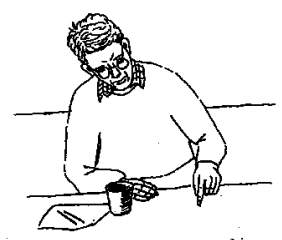

Figure 1. Pointing gesture (line 5)

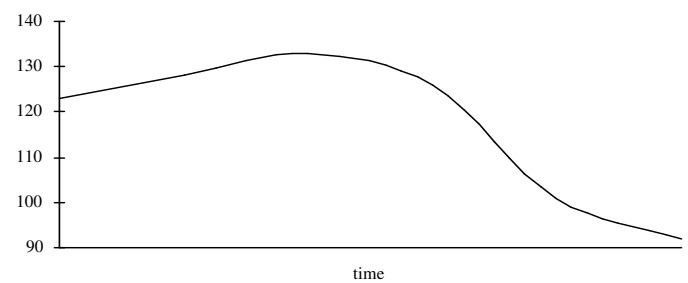

Figure 2. Pitch contour of hun ('she') as pronounced by A. in the 'renovation' sequence (acoustic measurement using Signalyze 3.12 on a Macintosh computer) 
Earlier in the conversation, A. had used pointing gestures and finger drawings on the table to explain the geographic location of the physiotherapy institute. Thus a specific spot on the table had been established as a reference point for the 'institute', and A. is now using this point to refer gesturally to a dislocated entity.

Having initiated a contribution non-verbally and verbally, A. seems to have reached a transition relevance place. It is not evident, though, that $\mathrm{M}$. interprets the pronoun as turn-final, cf. her somewhat delayed response (line 7). During the pause preceding M.'s utterance, A. keeps looking at the table, not at M., an indication that he may not yet have finished his contribution. Furthermore, the lexical form of A.'s verbal contribution is not what one would ordinarily expect for the first mention of a referent (Fox 1987), and M. might therefore reasonably expect some more information to follow. At this point, M. does not seem to have anything substantial to contribute. Rather, she produces a minimal utterance ( $j a$ 'yes') as a passing turn.

A. does not, however, provide new information about the referent; instead he non-verbally manifests the importance of his pointing gesture by focusing visually on the table again and making three taps on the point he has located there. Non-verbally he reiterates the content of his contribution in lines 5-6. He also moves his gaze to $\mathrm{M}$. (in contrast to what he did after the utterance in line 6), thereby signalling a shift of discursive roles. This time M. interprets A.'s contribution as turn-final, and immediately responds with a first guess at who the referent of hun 'she' might be: fysioterapeuten 'the physiotherapist' (line 8). This guess is not accepted as satisfactory by A., though. At this stage, the participants have completed one hint-and-guess cycle: a tripartite structure consisting of a hint, a guess and an evaluation.

\section{The second attempt at establishing reference}

\section{A: ..hun\} \\ 'she'}

\{A and $\mathrm{M}$ look at the table, then at each other. A: quick finger movement, then points at the table again\}

\section{$12\{\{d u\}\}$}

$\{\{$ A looks at the table $\}\}$ 'you'

Following the dismissal of M.'s guess, A. makes another pointing gesture at the designated point on the table, overlapped by a verbal utterance: the pronoun hun 'she', again pronounced with a falling pitch contour (line 11). 
These non-verbal and verbal actions constitute the second attempt at establishing reference, and the initiation of a second hint-and-guess cycle. The conditionally relevant next utterance at this point is a guess from $\mathrm{M}$. There are clear similarities between this place in the sequence and the transition between lines 6 and 7-8, where indeed a change of speakers occurs. However, here (line 11) M. does not give any clear signals of turntaking, and A. does not leave much room for turn-transition either. One reason for this may be that this second attempt is more or less identical to the first one, which did not provide sufficient information for M. to make an acceptable guess. The repetition of the hint in line 11 could be interpreted as a way of gaining time, or as a way of emphasising the importance of the components of the hint (the referent is female and connected to the physiotherapy institute).

Rather than waiting for $M$. to make a new guess, A. fairly quickly initiates a new turn in line 12 , when he utters the word $d u$ 'you, sg.' and simultaneously moves his gaze to the table. In this context, the pronoun functions as an attention-securing device that also provides interactional space for an extended turn. The combination of the pronoun and the movement of the gaze allows A. to secure the attention of his recipient for an extended turn as well as direct the recipient's attention at a specific target.

\section{The third attempt at establishing reference}

\section{A: $\{\ldots(7.0)\}$}

$\{\mathrm{M}$ looks at the table. A writes '75' with his index finger on the table. Pause of 1.7 seconds: M starts moving her lips and gets a puzzled look on her face. M points to/looks at paper/pencil on the table; A starts pointing towards the point on the table\}

$14 \mathrm{M}:\{\{k a n d u$ skrive $p \stackrel{\circ}{=}=\}\}$

$\{\{\mathrm{M}$ points to paper/pencil, A moves his hand to take the pencil $\}\}$

'could you write on'

$15 \quad$ med blyant $i$ stedet?\}

\{A takes the pencil, $\mathrm{M}$ leans forward and looks at the paper\}

'with a pencil instead'

$16 \mathrm{~A}:\{\{\ldots(7.6)\}\}$

$\{\{\mathrm{A}$ writes '75' on the paper; $\mathrm{A}$ and $\mathrm{M}$ look at the paper. A then looks at $\mathrm{M}\}\}$ 
17 M: \{syttifem?\}

\{A briefly moves his gaze to somewhere in front of him, then looks at M again\}

'seventy-five'

18 A: ..ja

'yes'

$19\{\{.$. hun $\}\}$

$\{\{\mathrm{M}$ looks at $\mathrm{A}\}\}$

'she'

20 M: \{... (1.5) var det en gammel dame der på syttifem år?\}

\{A looks at $\mathrm{M}$, bends slightly forward, looks at the table, points at the written number, looks at $\mathrm{M}$ again. $\mathrm{M}$ looks at $\mathrm{A}$ \}

'was there an old lady there of seventy-five years'

$21 \mathrm{~A}: \ldots(1.1)[j a]$

'yes'

$22 \mathrm{M}:$

$$
\text { [nei?] }
$$

'no'

$23 \mathrm{~A}:\{\{. .<\mathrm{A} m e n\}\}\{<\mathrm{F}$ jo $\mathrm{F}>\mathrm{A}>$

$\{\{$ A looks at the paper. M looks at $\mathrm{A}\}\}$

'but' 'yes'

$24 \quad \ldots[j a]$

'yes'

$25 \mathrm{M}: \quad$ [var det det?]

'was there'

26 A: ja

'yes'

$27 \quad j a\}$

$\{$ A looks at $\mathrm{M}$, nods at affirmative utterances. $\mathrm{M}$ looks at $\mathrm{A}$ \}

'yes'

$28 \mathrm{M}$ :.. en annen.. som $=$ sku trene?

'another one who was exercising' 
29 A: $\{\{. . n e i !\}\}$

$\{\{$ A slightly shakes his head $\}\}$

'no'

$30 \mathrm{M}:(0)$ nei

'no'

31 M: $\{\ldots(1.0)\}<$ A er fysioterapeuten din \{\{syttifem år? <@ nei! @> A>

$\{$ A shakes his head

'is your physiotherapist seventy-five years old no'

$32[@=]$

33 A: $[$ nei=]

'no'

$34 \quad . .<\mathrm{X} . e h=. \mathrm{X}>\}\}$

$\{\{$ A looks at the paper, moves his hand towards $\mathrm{M}$, towards himself, takes the pencil\}\}

The third attempt at establishing reference is managed within a fairly long sequence with several inserted side sequences and points of negotiation of both participant framework and interaction pattern. Following A.'s preannouncement of an extended turn, $\mathrm{M}$. adopts the role as an attentive recipient, and moves her gaze to the table in line 13. A. continues his turn non-verbally by writing the number 75 with his finger on the table. This is the initiation of the third attempt at establishing reference, and A. here makes use of writing as an alternative and augmentative form of communication. His writing does not leave any traces, though, and from the facial expression of M. (puzzled look), it may be assumed that she has difficulties understanding what he has written. She thus initiates a metacommunicative side sequence (Jefferson 1972) to sort out this problem of understanding (lines 14-15). A. responds adequately non-verbally by reaching for the pencil, and reiterating his writing on paper. The side sequence is closed by A. moving his gaze to M., thereby indicating a shift of speakers (line 16).

A. has now provided a new hint, not merely repeated an earlier one, and he may therefore reasonably expect $M$. to make another guess. However, in line 17, M. initiates another metacommunicative side sequence, reading out aloud what $\mathrm{A}$. has written. In this side sequence, the degree of understanding is monitored, and M. displays a need for processing time. 
Significantly, she does not meet A.'s turn-giving gaze, which may also indicate that she is not prepared to make a new guess as yet. The side sequence is closed by A.'s affirmative $j a$ 'yes' in line 18. However, M. has not moved her gaze away from the paper, thus A. fairly quickly elaborates on the turn by reiterating the pronoun hun 'she' (line 19), and simultaneously M. moves her gaze to A., signalling more willingness to take the next turn.

In the course of lines 13-19, then, a third attempt at establishing reference constitutes the contribution from A. The main parts of this contribution are the non-verbal component (line 13) and the verbal component (line 19), and between these, two metacommunicative side sequences are inserted, one repairing and one monitoring the immediately preceding interaction.

Following the transition relevance place in line 19, there is a fairly long pause of about 1.5 seconds (line 20) indicating problems in the turn-taking procedure. This pause can be interpreted in at least two ways: from M.'s point of view, as a processing pause, and from A.'s point of view, as a way of creating an opportunity for a new guess from M. In order to have his contributions established in the interaction, A. is heavily dependent on an interlocutor who can make guesses at what his verbally incomplete utterances may refer to. However, this also means that his co-participant must be given opportunities at appropriate points in the interaction to make these guesses. In other words, having issued a new hint, A. must leave the floor for his conversational partner to make a new guess.

However, A. does not completely leave the floor in line 20. During the pause he starts some non-verbal actions: he makes a bodily gesture (pulling his shoulders together, raising them slightly, before resuming an upright position) and a pointing gesture towards the number written on the piece of paper. The positioning of the non-verbal actions at this point is similar to what happened earlier in the interaction, during the pause in line 8 , where A. non-verbally reiterated an earlier contribution. Both in line 8 and 20, A. performs non-verbal actions at sequential positions in the interaction where a contribution - a new guess - that can be anticipated from his co-participant is somewhat delayed. In both instances the non-verbal actions function as additions to the earlier parts of the contributions rather than as new and informationally independent parts of the contributions. M. does not seem to pay particular attention to these additional non-verbal actions when making her guesses.

In line 21, A. responds affirmatively to M.'s new guess in line 20. However, the pause preceding A.'s response may suggest an element of dispreference (Levinson 1983: 334). This interpretation is strengthened by the fact that following the verbal response, A. immediately removes his gaze from $\mathrm{M}$. to the piece of paper on the table. M. clearly interprets the pause in this way as seen in her questioning nei 'no' (line 22) delivered in overlap 
with A.'s verbal response. However, A.'s affirmative response is not totally wrong, either, as can be seen from the fact that when challenged with the opposite interpretations (lines 22 and 25), he strongly reiterates the affirmation (lines 23-24, 26-27). The interaction in lines $22-27$ is a side sequence - a repair sequence - in which the correct interpretation of the verbal exchange in lines $20-21$ is negotiated. The participants are looking at each other, indicating co-orientation towards each other and towards a common interactional goal.

The main sequence of the interaction - the hint-and-guess sequence - is resumed in line 28. The three main types of components that are employed in this sequence type (the hints, the guesses and the evaluations) make up a tripartite structure that can be recycled. However, the components do not always follow each other in this order. The structure can alternatively be organised as an initial hint followed by a shorter or longer chain of adjacency pairs consisting of guesses and subsequent refusal or partial acceptance.

At this point in the interaction, there is an example of this kind of chain of adjacency pairs which starts with the hint introduced in line 13 and repeated in line 16 (i.e. the written number 75) followed by M.'s guesses in lines 20, 28 and 31. All of these guesses are partly or wholly refused as acceptable interpretations (lines 21/23, 29, 33). Following each completed cycle of guess and acceptance/refusal, there is a point in the interaction where the participants must negotiate which pattern to follow in the subsequent interaction: the tripartite pattern or the adjacency pair pattern. This negotiation of interaction pattern is linked to a negotiation of participant framework or division of discursive roles (Goffman 1981 [1979]). The tripartite pattern requires initiatives from A. (i.e. he has to adopt a production role), whereas the adjacency pair pattern allows A. to adopt a primary role as recipient.

The chain of adjacency pairs comes to a close in lines 34-35, as A. takes the turn to give a new hint. M. has not been able to come up with an acceptable guess; in fact, her suggestion in line 31 is clearly perceived by herself as somewhat far-fetched, cf. the rush-through that she makes following the word air 'old' into a denial (nei 'no'), accompanied by unilateral laughter which displays the non-seriousness of her guess and highlights the fact that she is having problems at this point making a better guess. At this point, A. starts signalling, non-verbally as well as verbally, that he will take the next turn, thus projecting a change in the interaction pattern from the chain of adjacency pairs to the main pattern initiated by a new hint. 


\section{The fourth attempt at establishing reference}

35 A: .. du

'you'

$36\{\{\ldots(4.0)\}\}$

$\{\{\mathrm{A}$ taps once with the pencil on the paper, looks at $\mathrm{M}$, then looks in front of himself, bends slightly forward, sets up an angry face and tightens his fist in front of his face, moving his lips as if speaking, redirects his gaze at $M$, still with the angry face and the bent position\}\}

37 hun

'she'

$38 \mathrm{M}$ :.. hvem- hvem \{var det?\}

\{A still leaning forward, ordinary face expression\}

'who- who was that'

39 s- som [var] syttifem år?

'who was seventy-five years'

40 A:

$$
[<\mathrm{P}<\mathrm{X} . e h=. \mathrm{X}>\mathrm{P}>]
$$

$41 \mathrm{~A}:\{\{\ldots(23.0)\}\}$

$\{\{$ A looks searchingly around the room, looks at $M$, then at the table, takes the pencil, starts tracing the number he has written on the paper, points to the number, looks away\}\}

$42 \mathrm{M}:$ : var det en dame som var syttifem [år?]\}

\{A looks at $\mathrm{M} . \mathrm{M}$ is nodding

'was there a lady who was seventy-five years'

43 A:

$$
\begin{aligned}
& {[j a]} \\
& \text { 'yes' }
\end{aligned}
$$

$44 \mathrm{M}:(0)$ ja

'yes'

The turn-taking signals that A. displays from mid-line 31 onwards, are followed by the pronoun $d u$ 'you, sg.' in line 35, which again functions as an attention-securing device, implicitly also projecting that there is more to 
come. Following the pronoun, A. makes a tapping gesture on the piece of paper with the pencil and looks at M. The gesturing with the pencil may indicate the focus of attention, whereas the shift of gaze signals a change of participant framework, where A. adopts the speaker role and therefore needs to secure the attention of his recipient. A.'s subsequent contribution in lines $36-37$ is again constructed as a non-verbal act (a bodily gesture, cf. Figure 3) followed by a verbal act (the pronoun hun 'she'). Even though the non-verbal part is presented before the verbal part, it is significant to note that A. maintains the position of the bodily gesture during the utterance of the pronoun; in fact, he holds the gesture until he gets a response from M. In other words, the two components of the utterance are fused in a way that indicates that they are to be interpreted as one larger component.

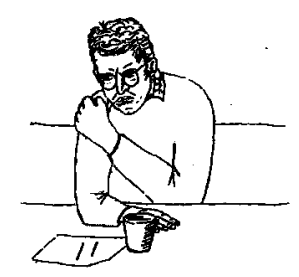

Figure 3. Mime posture I (line 36)

Once again, A. also uses gaze to demarcate a specific part of a turn from the rest of the turn. When starting the non-verbal action, he withdraws his gaze from M., and at the end of the bodily gesture he redirects his gaze at her. This also supports the interpretation of the pronoun as turn-final; by gazing at the recipient, A. signals an upcoming transition relevance place and selects the recipient of the gaze as the next speaker (cf. line 11).

A. has now left the floor to M., who is expected to make a new guess. However, she seems unable to fulfil her obligation, and instead returns the turn to A. by asking him directly who the referent of hun 'she' is (lines 3839). Although formally a request for information, functionally, her question is a way of restating the topic of immediate concern in this part of the interaction and highlighting the fact that she is unable to make a new guess, even though - through taking the turn - she implicitly acknowledges that this is what is expected of her at this point in the conversation.

A. is apparently not able to give an immediate or more satisfactory response. Despite a weak indication of willingness to take the turn (line 40), he withdraws his gaze from M. and looks somewhat searchingly around the room (line 41). He then redirects his gaze at M., who at this point (about 3.5 
seconds after her utterance), signals a non-speaking position by returning from a forward-bending position to an upright, more neutral position. Observing that she is not going to take this turn, A. again turns his gaze at the table, picks up the pencil and starts tracing over the number he has written on the paper (75). After approximately 18 seconds, he puts the pencil down, points to the number and looks away (not towards M.). This is the first unequivocal signal of a word finding difficulty.

These approximately 23 seconds represent a kind of "time-out" in the interaction. At the beginning of this break there is a phase in which the immediate participant roles are negotiated by means of gaze and body posture. Contrary to most such negotiations, the concern of the participants seems to be to avoid the turn, rather than to secure it for themselves. When it has been made clear that $M$. is not going to take this turn, A. engages in gesturing which does not seem to be communicative in the sense that it does not seem to be intended to be recognised as a substantial contribution to the interaction. Evidence in favour of this interpretation is the fact that A. does not secure the attention of his recipient or point out any direction of potential focus of attention. At the end of his tracing movement with the pencil, he once more points to the number on the paper. This could more easily be interpreted as an act of communication; however, A. does not direct his gaze at M. at this point either; on the contrary, he looks away, indicating that they are still temporarily "out" of the interaction.

Even though A.'s gesturing at this point is interpreted as noncommunicative (not intended to convey a specific message to a particular recipient) it is not insignificant. By filling this time with an action of some sort, A. actually creates a time-out from the communicative project he is involved in without signalling a final break with the project. In other words, he adheres to the temporal imperative (Clark 1996: 267). A. may need this time-out in order to be able to make a new attempt at referring. However, had he not performed any kind of action in this break, his interlocutor would have been more likely to interrupt, with the risk for him of losing the opportunity for continuing his project altogether. Apart from providing him with necessary processing time, the seemingly pointless gesturing in line 41 also allows $\mathrm{A}$. to present himself as an interactionally and socially competent participant.

A. ends the time-out with a pointing gesture, which, even though it is not framed as a directed act, is taken up by $\mathrm{M}$. as she starts the main project again in her turn in line 42 . This turn represents a return to the interaction, firstly by the mere fact that the turn-taking process is resumed. The participants enter complementary participant roles, M. as speaker and A. as recipient (cf. the redirection of his gaze to $M$. in line 42). Secondly, the content of the turn signals a return to the interaction. The turn repeats the 
question in lines 38-39; however, this time not in the form of a wh-question but rephrased as a yes/no-question, to which it is presumably easier for A. to respond. In the same way that the question in lines 38-39 was not primarily a request for information, the question in line 42 has the function of restating common knowledge rather than requesting information. While uttering this question, $\mathrm{M}$. is nodding, thus signalling that the form of the utterance does not actually reflect the function of it (cf. also the fact that resumptions often take the form of repetitions). After a temporary break from a project, there is a need to agree on how far one has got, and such an agreement is reached through the restating question and the exchange of agreement tokens (lines $42-44)$.

\section{The fifth attempt at establishing reference}

$45 \mathrm{~A}:\{\{. . \mathrm{men}\}\}$

$\{\{$ A starts moving his gaze towards the paper $\}\}$

'but'

$46 \quad\{. e h=$.

\{A looks at the paper, points to the number\}

$47 \quad\{\{\ldots(1.6)\}\}$ dame

$\{\{$ A looks in front of himself $\}\}$

'lady'

$48 \quad\{\ldots(1.6)\}$

$\{$ A looks at $M$, with an angry face $\}$

\{ \{ pusse opp

'renovate'

49 nei!\}\}

$\{\{$ A looks in front of himself, angry face, shakes his head at pusse opp, tightens his fist and 'knocks' in the air in front of him at nei\}\}

'no'

50 M: $\{\ldots$ (1.5) $\}$

$\{$ A looks at $\mathrm{M}\}$

$\{\{a ̊ h=$ !

'oh' 
$\{\{$ A stretches arm towards $\mathrm{M}$, resumes an upright position; $\mathrm{M}$ makes an 'astonished' face\}\}

'is it she who owned the house'

52 A: $\{\ldots$ akkurat $\}$

\{A starts smiling

'exactly'

M. has so far not been able to make an acceptable guess. A new hint is needed, and A. obviously realizes this, as he starts initiating a fifth attempt at referring in line 45 . His utterance men 'but' here signals that the level of knowledge that the participants have reached about the identity of the referent is only partly correct. Their common understanding so far implies that they mutually know that hun 'she' refers to an old lady with some connection to the physiotherapy institute. However, this is not sufficient for the purpose of A.'s main project (explaining why the physiotherapy institute is not going to be renovated). For that, a more accurate reference must be established.

Simultaneously with the verbal utterance in line 45 , A. starts moving his gaze towards the piece of paper, pointing to the number written on it, thus indicating that this piece of information (the number 75 ) is still relevant. Then there is a pause of 1.6 seconds during which he moves his gaze to a neutral position in front of himself (cf. Figure 4) before he utters the noun dame 'lady' in line 47 . This is the first time he refers to the referent by a noun phrase rather than by a pronoun.

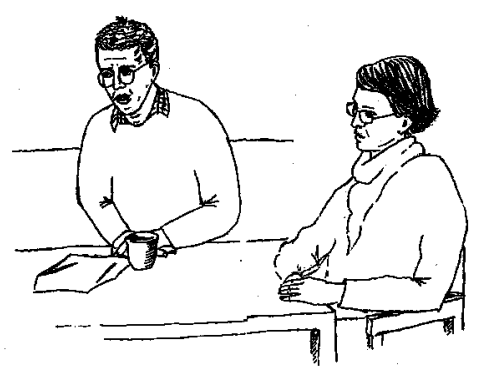

Figure 4. Gaze direction (line 47)

Following the noun dame 'lady', there is a new pause of approximately 1.6 seconds in which several tasks are accomplished. Firstly, A. moves his gaze to M., securing her attention, and secondly, he gets into the mime position as 
an angry, old lady. Having thus "set the scene", he goes on with two verbal utterances: pusse opp 'renovate' and nei 'no' in lines 48-49, accompanied by gestures. His gaze is in a neutral, forward position, and his body posture and facial expression are clearly meant to resemble those of an angry, old lady. Overlapping with the first verbal utterance (line 48) he shakes his head, and overlapping with the second verbal utterance (line 49) he makes a hitting gesture with a tightened fist in front of himself (cf. Figure 5). The 1.6 second pause not only gives A. the opportunity to set the scene, but it also functions as a demarcation of the following sequence (i.e. a dramatisation or reported speech sequence, cf. Wilkinson 2000; Lind 2002a,b; Wilkinson, Beeke and Maxim 2003a), setting it apart from the preceding utterances.

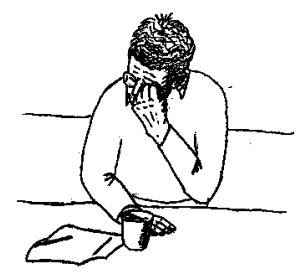

Figure 5. Mime posture II (line 49)

Following this reported speech sequence, there is a pause of 1.5 seconds in which A. moves his gaze to M., thus signalling the end of his turn. However, he holds the gesture until M. starts responding (line 50) with a token of displayed recognition: $a h=$ ! 'oh' (cf. Heritage 1984). When M. starts responding, A. starts resuming his upright, relaxed position and stretches an arm towards his co-participant, in recognition of her correct guess. M. does not only display recognition; she also checks her interpretation in a (partial) reformulation of the reported speech sequence (line 51). The reformulation is partial because it only deals with the referent part of A.'s contribution, not the predication part. This check is the final guess at who the referent is, and it is accepted by A. as a correct interpretation (line 52).

\title{
Celebration of the solution
}

\author{
53 A: $\{\{[<@ t a k k @>]\}\}$ \\ $\{\{$ A turns away from $\mathrm{M}$, smiling $\}\}$ \\ 'thanks'
}




\section{$54 \mathrm{M}: \begin{gathered}{[j a h a=]} \\ \text { 'yes' }\end{gathered}$}

55 A: \{@@\}

\{A turns to gaze at $\mathrm{M}$, broad smile and laughter; upright position fully resumed

Following the resolution of the reference project is an exchange of acknowledgement tokens and tokens of potential topic closure in lines 5355 . Hint-and-guess sequences are normally concluded by long confirmation phases - often longer than this one - in which the participants display their mutual agreement about the solution of the communicative project of the sequence (Laakso and Klippi 1999). Since communicative projects, such as the establishment of reference or the search for a specific word, usually take a lot of interactional effort in aphasic interaction, it seems only natural that a certain amount of effort is put into confirming and "celebrating" the solution and closing the sequence. Rather than focusing on what is not (or has not been) successful, the participants in closing such sequences prevalently focus on the achievement of success of their interaction.

\section{Summary of the structure and function of the 'renovation' sequence}

Over the last pages, a fairly detailed descriptive analysis has been given of the establishment of a contribution to conversation by a speaker with severe language difficulties. In summary, the analysed sequence consists of three phases: firstly, an opening phase (lines 1-4), in which the main project of the sequence is introduced and a framework for co-participation is established; secondly, a hint-and-guess phase (lines 5-52), in which five regularly structured hints are presented by the aphasic participant, and guesses are made by the non-aphasic participant, the last guess being accepted as satisfactory; and finally, a closing phase (lines 53-55), in which the solution is confirmed and celebrated.

The hint-and-guess phase consists of two kinds of structures: the tripartite structure of hint, guess and acceptance/refusal and the adjacency pair structure of guess and acceptance/refusal (lines 20-31). This phase is also interrupted by several side sequences as well as a calculated time-out from the interaction. These interruptions do not disrupt the main project, although, when the break is long (as in the case of the time-out), the framework for co-participation has to be re-established. The fact that the main sequence is maintained even though the participants move in and out 
of it in side sequences and temporary breaks illustrates the orderliness with which the whole sequence is managed.

The hints by the aphasic speaker in this sequence are structured in a regular fashion. All of them consist of non-verbal acts combined with a verbal utterance, which in the first four instances is a linguistic expression normally used for locally subsequent rather than initial reference (Schegloff 1996: 450f): the pronoun hun 'she'. The non-verbal parts of the hints differ, though, from pointing to writing to the execution of a whole body gesture, making the hints different despite the identical form of the verbal components. In the last hint, the verbal part of the utterance is far more elaborate as the aphasic participant makes use of a displaced mode of speaking, taking on the role of another person and seemingly expressing "her" opinion in "her" words.

We may wonder why this solution was not attempted earlier, as it is obviously successful, economic and elegant in relation to the problem underlying this sequence. One reason why this was not the first attempt at establishing reference may have been the need to establish some common knowledge about the referent before it was possible to introduce her as the speaker in a reported speech sequence. The attempts at establishing reference seem to be structured in a way that allows the participants to move from simpler to more complex "phrases". Hence, the way A. has structured his contributions in this sequence - the grammar of his contributions, so to speak - may be described as interactionally motivated or, in other words, adapted to the requirements of conversation as a particular communicative activity (cf. Heeschen and Schegloff 2003; Wilkinson, Beeke and Maxim 2003b).

Sequences in interaction are used for particular purposes; that is, they have certain functions; they are employed to perform certain actions. Hintand-guess sequences can, as Laakso and Klippi (1999) have found, be used to solve a particular problem of word finding, locally manifested as such. However, as the present analysis displays, hint-and-guess sequences can also - simultaneously - be used to give the aphasic participant an opportunity to make a self-initiated, extended contribution, that is, a contribution over which the aphasic participant has primary control and authority and which consists of at least a reference part and a predication part. In so far as participation in social - including conversational interaction is vital for the well-being and quality of life of each individual person, being allowed to express oneself by whatever means available is essential, not least for people with a speech and language disorder such as aphasia. 


\section{Concluding remarks}

The analysis presented here lends support to earlier studies that have demonstrated the existence of a sequence type frequently used in aphasic conversation (although not exclusively in such interactions): the so-called hint-and-guess sequence. Overall, the analysis confirms the structure and function of such sequences as described by Laakso and Klippi (1999), with the exception that an overt problem-establishment phase marked by, for instance, gaze withdrawal, hesitation markers, metacommunicative expressions etc. is not found. This does not, of course, exclude the existence of an underlying problem of word finding acting as a trigger for the sequence.

Based on Norwegian data, the study adds to the existing knowledge base on aphasia and conversation, in particular by demonstrating the aphasic participant's ability to make himself understood by using several modalities of communication - speaking, writing, gesturing - with different underlying semiotic systems in conjunction, and by situating his parts of the contribution in relation to the particular, evolving sequential context (cf. Goodwin 2003; Klippi 2003).

The analysis also reveals, in line with prior research, that in spite of what may at the outset seem like a disorderly piece of interaction due to the disorderly linguistic output of one of the participants, there is a striking orderliness in the sequence. This orderliness is demonstrably not an outcome of the actions of just one of the participants (the non-aphasic interlocutor) but is a product of the participants' joint efforts in negotiating meaning in a particular situation.

As a growing number of studies on different types of speech and language disorders are conducted within a conversation analytic framework, questions concerning the applicability of this framework to the practices relevant to speech and language disorders are increasingly pertinent. Such practices include speech and language therapy in different settings (e.g. individual therapy, group therapy and "indirect" therapy, aimed at family members and others close to the impaired speaker), as well as training of speech and language therapists. Today, it is common knowledge that conversation is the primordial site of language use and the context of communication in which identities and relationships are constantly being shaped and reshaped. We also know that a general goal of aphasia therapy is an increased functional ability in everyday communication. In other words, conversation is - or ought to be - the natural locus for therapy. Furthermore, we know that a quite marked divergence between test performance and naturalistic behaviour is not uncommon in aphasics (cf. e.g. Simonsen and Lind (2002), another case study of A., which finds marked 
differences between the ability to produce verbs in a test and in conversation). In order to develop therapy programmes that actually target what we would like them to target, we need know the strengths and weaknesses of the client in everyday communication, and this knowledge should be based on a systematic methodology rather than on impressionistic and anecdotal data.

Conversation analysis offers a methodology for systematic description and exploration - of the means and processes of everyday interactions, and because it is empirically grounded as well as focused on the practical accomplishments of interaction, it should be - and increasingly is (cf. earlier references to this type of approach to assessment and rehabilitation) - a useful complementary addition to the "toolbox" of speech and language therapists. However, for conversation analysis to be useful in relation to an applied field, such as speech and language therapy, boundaries between application and ("pure") research should be broken down. The professional (the speech and language therapist) has to perform conversation analysis within his or her practice in much the same way as a researcher of conversation. Application will then consist in challenging pre-established assumptions, developing a sensitivity towards the intricacies of conversation, directing attention to possible solutions to interactional problems, and raising the awareness of the professional in relation to his or her own practice (cf. Richards 2004: 5f). The main advantage of conversation analysis here lies in the systematic methodology for describing conversational structure and conversational actions that this perspective offers, as well as in the painstaking insistence on empirical grounding. As with any other methodology, conversation analysis has to be taught, and an important challenge for the application of this methodology within speech and language therapy is the extent to which it is embraced within professional training of speech and language therapists in different countries.

\section{Acknowledgement}

This article is based on one of the chapters of my Dr.Art. thesis (Lind 2002a). I thank the aphasic participant in the conversation for allowing me to record and study our interaction. I also thank dr. Ray Wilkinson and prof. Inger Moen for extensive discussions of my data and analyses, Kirsten Sannerhaugen for preparing the drawings, and the editors and referees for helpful suggestions on an earlier version. 


\section{References}

Anward, J. (2003) Own words: on achieving normality through paraphasias. In C. Goodwin (ed.), Conversation and brain damage. Oxford University Press. 189-210.

Bremer, K., C. Roberts, M.-T. Vasseur, M. Simonot and P. Broeder (1996) Achieving understanding: discourse in intercultural encounters. London: Longman.

Brown, G. (1995) Speakers, listeners and communication: explorations in discourse analysis. Cambridge University Press.

Caplan, D. (1987) Neurolinguistics and linguistic aphasiology. Cambridge University Press.

Clark, H.H. (1996) Using language. Cambridge University Press.

Code, C. (1989) Symptoms, syndromes, models: the nature of aphasia. In C. Code (ed.), The characteristics of aphasia. London: Taylor and Francis. 1-22.

Collins, S. and I. Markovà (1995) Complementarity in the construction of a problematic utterance in conversation. In I. Markovà, C.F. Graumann and K. Foppa (eds.), Mutualities in dialogue. Cambridge University Press. 238-63.

Damico, J.S., M. Oelschlaeger and N. Simmons-Mackie (1999) Qualitative methods in aphasia research: conversation analysis. Aphasiology 13: 667-79.

Du Bois, J.W., S. Schuetze-Coburn, S. Cumming and D. Paolino (1993) Outline of discourse transcription. In J.A. Edwards and M.D. Lampert (eds.), Talking data. Transcription and coding in discourse research. Hillsdale, N.J.: Lawrence Erlbaum. 45-89.

Fox, B.A. (1987) Discourse structure and anaphora. Written and conversational English. Cambridge University Press.

Goffman, E. (1981 [1979]): Footing. In E. Goffman (ed.), Forms of talk. Oxford: Blackwell. 124-59.

Goodwin, C. (1995) Co-constructing meaning in conversations with an aphasic man. Research on Language and Social Interaction 28: 233-60.

- (2003) Conversational frameworks for the accomplishment of meaning in aphasia. In C. Goodwin (ed.), Conversation and brain damage. Oxford University Press. 90116.

Goodwin, M.H. and C. Goodwin (1986) Gesture and coparticipation in the activity of searching for a word. Semiotica 62: 51-75.

Heeschen, C. and E.A. Schegloff (2003) Aphasic agrammatism as interactional artifact and achievement. In C. Goodwin (ed.), Conversation and brain damage. Oxford University Press. 231-82.

Heritage, J. (1984) A change-of-state token and aspects of its sequential placement. In J.M. Atkinson and J. Heritage (eds.), Structures of social action. Studies in conversation analysis. Cambridge University Press. 299-345.

Jefferson, G. (1972) Side sequences. In D. Sudnow (ed.), Studies in social interaction. New York: The Free Press. 295-331.

-(1989) Preliminary notes on a possible metric which provides for a 'standard maximum' silence of approximately one second in conversation. In D. Roger and P. Bull (eds.), Conversation. An interdisciplinary perspective. Clevedon: Multilingual Matters. 166-96.

Jordan, L. and W. Kaiser (1996) Aphasia - a social approach. London: Chapman and Hall. 
Klippi, A. (1996) Conversation as an achievement in aphasics. Helsinki: Suomalaisen Kirjallisuuden Seura.

- (2003) Collaborating in aphasic group conversation: striving for mutual understanding. In C. Goodwin (ed.), Conversation and brain damage. Oxford University Press. 117-43.

Laakso, M. (1997) Self-initiated repair by fluent aphasic speakers in conversation. Helsinki: Finnish Literature Society.

Laakso, M. and A. Klippi (1999) A closer look at the 'hint and guess' sequences in aphasic conversation. Aphasiology 13: 345-63.

Labov, W. and D. Fanshel (1977) Therapeutic discourse: psychotherapy as conversation. Orlando, Fla.: Academic Press.

Lesser, R. (1978) Linguistic investigations of aphasia. London: Edward Arnold.

Lesser, R. and L. Perkins (1999) Cognitive neuropsychology and conversation analysis in aphasia. An introductory casebook. London: Whurr Publishers.

Levinson, S.C. (1983) Pragmatics. Cambridge University Press.

- (1992 [1979]) Activity types and language. In P. Drew and J. Heritage (eds.), Talk at work. Interaction in institutional settings. Cambridge University Press. 66-100.

Lind, M. (2002a) Conversational cooperation: the establishment of reference and displacement in aphasic interaction. A Norwegian case study. Unpublished Dr.Art. thesis, Faculty of Arts, University of Oslo.

- (2002b) The use of prosody in interaction: observations from a case study of a Norwegian speaker with a non-fluent type of aphasia. In F. Windsor, L. Kelly and N. Hewlett (eds.), Investigations in clinical phonetics and linguistics. Mahwah, N.J.: Lawrence Erlbaum. 373-89.

Linell, P. (1991) Dialogism and the orderliness of conversational disorders. In J. Brodin and E. Björck-Åkesson (eds.), Methodological issues in research in augmentative and alternative communication. Stockholm: The Swedish Handicap Institute. 9-21.

- (1998) Approaching dialogue. Talk, interaction and contexts in dialogical perspectives. Amsterdam: John Benjamins.

Lock, S., R. Wilkinson and K. Bryan (2001) SPPARC: Supporting partners of people with aphasia in relationships and conversation. Bicester: Speechmark.

Lubinski, R., J. Duchan and B. Weitzner-Lin (1980) Analysis of breakdowns and repairs in aphasic adult communication. In R. Brookshire (ed.), Clinical aphasiology conference proceedings. Minnesota: BRK Publishers. 111-16.

Ochs, E. and B.B. Schieffelin (1983) Acquiring conversational competence. London: Routledge and Kegan Paul.

Oelschlaeger, M.L. and J.S. Damico (2003) Word searches in aphasia: a study of the collaborative responses of communicative partners. In C. Goodwin (ed.), Conversation and brain damage. Oxford University Press. 211-27.

Pomerantz, A. (1984) Pursuing a response. In J.M. Atkinson and J. Heritage (eds.), Structures of social action. Studies in conversation analysis. Cambridge University Press. 152-66.

Pomerantz, A. and B.J. Fehr (1997) Conversation analysis: an approach to the study of social action as sense making practices. In T.A. van Dijk (ed.), Discourse as social interaction. Discourse studies: a multidisciplinary introduction. Volume 2. London: SAGE Publications. 64-91. 
Pound, C., S. Parr, J. Lindsay and C. Woolf (2000) Beyond aphasia. Therapies for living with communication disability. Bicester: Speechmark.

Richards, K. (2004) Introduction. In K. Richards and P. Seedhouse (eds.), Applying conversation analysis. New York: Palgrave Macmillan. 1-15.

Schegloff, E.A. (1993) Reflections on quantifications in the study of conversation. Research on Language and Social Interaction 26: 99-128.

-- (1996) Some practices for referring to persons in talk-in-interaction: a partial sketch of a systematics. In B. Fox (ed.), Studies in anaphora. Amsterdam: John Benjamins. 437-85.

Simonsen, H.G. and M. Lind (2002) Past tense expression in a Norwegian man with Broca's aphasia. In F. Windsor, L. Kelly and N. Hewlett (eds.), Investigations in clinical phonetics and linguistics. Mahwah, N.J.: Lawrence Erlbaum. 45-56.

ten Have, P. (1999) Doing conversation analysis. A practical guide. London: SAGE Publications.

Whitworth, A., L. Perkins and R. Lesser (1997) Conversation analysis profile for people with aphasia. London: Whurr Publishers.

Wilkinson, R. (1999) Introduction. Aphasiology [Special issue on conversation analysis] 13: 251-8.

- (2000) The use of direct reported speech and mime in speakers with aphasia in conversation. Paper presented at The 7th International Pragmatics Conference, Budapest, July 2000.

- , S. Beeke and J. Maxim (2003a) Combining language and functional abilities: the use of enactment by speakers with aphasia in conversation. Paper presented at British Aphasiology Society Biennial International Conference, Newcastle, September 2003.

- (2003b) Adapting to conversation: on the use of linguistic resources by speakers with fluent aphasia in the construction of turns at talk. In C. Goodwin (ed.), Conversation and brain damage. Oxford University Press. 59-89.

[Received 4/6/04; revised 15/2/05] 


\section{Appendix - Key to transcription symbols}

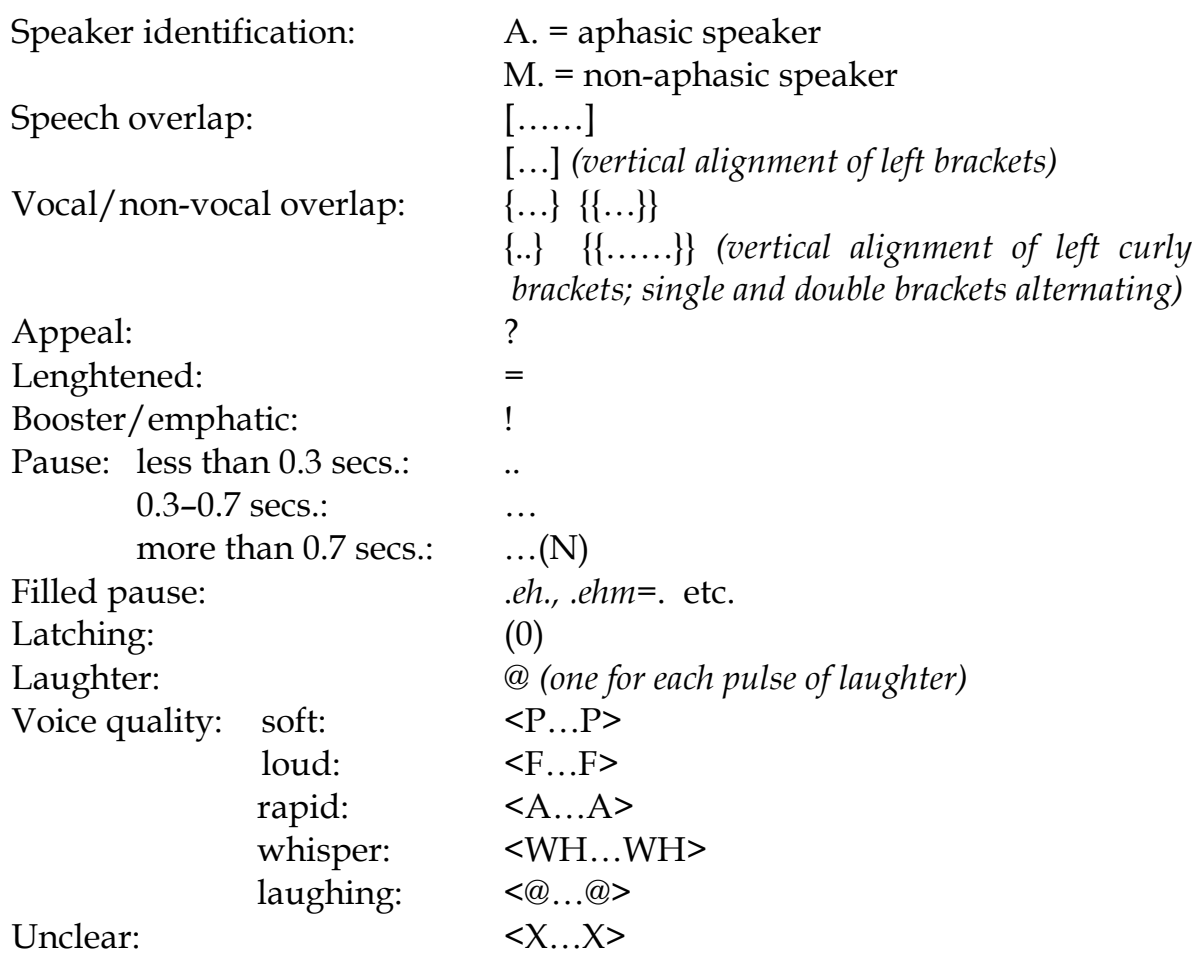

